\title{
Gender and the future of macroeconomics: an evolutionary approach
}

Sheila Dow ${ }^{1,2}$

Published online: 11 March 2020

(C) The Author(s) 2020

\begin{abstract}
Gender lends itself well to an evolutionary analysis which focuses on nonequilibrium change and transformation for individuals within society. Decomposition by such an important category as gender helps us understand the economy at the macro level, and design macroeconomic policy, better. It also provides the foundation for advocating equal gender rights and outcomes. But, where gendered policy issues arise in mainstream macroeconomics (income maldistribution, labour market composition, etc.), the subject matter is narrowed by its microfoundations, by focusing on GDP growth and on suboptimal outcomes being explained by market imperfections. An approach which takes gender seriously requires the different epistemology which arises from feminism: it does not rely on dualistic categorisations, but builds on the idea of situated knowledge, which in turn requires a pluralist methodology and an acceptance of fundamental uncertainty. Such a methodology allows for emergent identity, for the cognitive roles of emotion and social convention, and for attention to power other than market power. Reflecting on how limited is the scope for mainstream macroeconomics to address gender, and what is required of a useful alternative, a political economy approach provides a clear focus for a more general discussion of the future of macroeconomics from an evolutionary perspective.
\end{abstract}

Keywords Gender· Evolution · Epistemology

JEL codes $\mathrm{B} 52 \cdot \mathrm{B} 54 \cdot \mathrm{B} 40$

Sheila Dow

s.c.dow@stir.ac.uk

1 Division of Economics, Stirling Management School, University of Stirling, Stirling FK9 4LA, UK

2 Department of Economics, University of Victoria, 3800 Finnerty Road, Victoria, BC V8P $5 \mathrm{C} 2$, Canada 


\section{Introduction}

Gender is a natural topic for an evolutionary economist, but not just because of the biological dimension. Rather, a gender focus has the potential to illuminate our understanding of identity, behaviours and institutional structures and their evolution. Further, where this is our focus, the way in which we build economic knowledge needs to be suited to this subject matter. We need an epistemology which addresses core gender issues: the emergent and non-dualistic nature of identity, the integral role of values and emotion in economic activity and in the building of knowledge about it, the importance of social convention and the role of power including, but not limited to, market power. Since these issues are not incompatible with evolutionary economics, there is scope for extending evolutionary analysis by learning from feminist epistemology.

Some gendered macroeconomics fits within the mainstream economic approach, and some feminist economists draw on mainstream tools. But the way in which we will consider here how gender enters into macroeconomic analysis reflects the more common approach to feminist economics which accords with the epistemology of non-mainstream economics. This approach to gender has parallels with the issues raised within evolutionary economics about macroeconomics more generally (see e.g. Foster 1987, 2011). Both involve a critique of the limitations placed by the methodological framework of the mainstream on considerations of non-equilibrium change but also of sources of stability in social conventions and in prior commitments. Indeed, Foster's (2018) evolutionary analysis of consumption provides a good bridge to consideration of gender and the household. The focus is different: while evolutionary economics focuses on reproduction through the lens of the firm, feminist economics focuses on labour force reproduction through the household within a wider social infrastructure. But both schools of thought emphasise the limitations placed on macroeconomic analysis by the mainstream reliance on the concept of the (rational, fullyinformed, atomistic) representative agent. Their critiques therefore falls squarely within the more general political economy critique of mainstream economics.

The approach to evolutionary economics to be applied here emphasises the importance of conventions or rules which adapt and evolve. This requires a focus, not purely on the macro or micro level, but rather on the intermediate 'meso' level (Dopfer et al. 2004; Dopfer and Potts 2008, pp. 20-21). Rules provide the foundation for individual behaviour, and in turn determine macroeconomic outcomes. Feminist economics similarly emphasises the effect of gendered social structures on individual behaviour and outcomes, and the scope for these structures to evolve, sometimes through conflict. To deal with gender simply by means of two (atomistic) representative agents - one male, the other female - is therefore to impoverish the potential for analysing the social conventions which govern gendered behaviour and the institutions which constrain it. Rather, gendered macroeconomics too needs to refer to the meso level. By exploring the application of a feminist epistemology to gendered macroeconomics, the hope is to contribute to an evolutionary perspective on gender.

In what follows, we explore first in more detail how mainstream macroeconomics deals with gender issues. We then consider what macroeconomics more generally entails, and consider how it has been, and can be, gendered from a different, non-mainstream, perspective. Finally, considering the further application of feminist economics to macroeconomics can have relevance also for the future of evolutionary macroeconomics. 


\section{Gender and macroeconomics}

Gender decomposition of macroeconomic aggregates enhances macroeconomics, even if it is limited to market activity and a dualistic gender characterisation. Any decomposition which differentiates between groups with different socio-economic characteristics serves to explain aggregate outcomes better and reveals routes for macroeconomic policy to improve macroeconomic outcomes. Further, focusing on gender differences reveals areas of social injustice, providing the basis for advocating a policy response. Yet even this narrow interpretation of the concept of gender barely features in mainstream macroeconomic theory.

Much of non-mainstream macroeconomics does not really consider gender much either. ${ }^{1}$ Yet here, we will explore the huge potential for doing so. Indeed, van Staveren $(2010,2017)$ spells out the potential for such synergies. The emphasis in feminist economics in the past has been at the microeconomic level, focusing particularly on the labour market and the household (see e.g. Folbre 1994). But a growing body of work on gendered macroeconomics is emerging (see Onaran 2015 for a review). For example, Seguino (2010) develops a gendered analysis of balance of payments constraints, while Onaran et al. (2018) $)^{2}$ develop a Post-Keynesian/post-Kaleckian gendered growth theory, focusing on inequality.

Conventional macroeconomics deals in aggregates - the (paid) labour supplied by all genders, the consumption by all genders and so on, suppressing gender differences and indeed inequality more generally (Galbraith 2019). But mainstream macroeconomics has been coming under sustained criticism, particularly given its failure to allow for, far less predict, the crisis. The lack of attention to distributional questions has contrasted with its growing political importance since the crisis. One source of the failings of mainstream analysis is widely seen as arising from the insistence on consistency of macroeconomic analysis with microfoundations expressed in terms of rational choice on the part of the representative individual. The universal nature of this individual (or even a pair of individuals, one male and one female) does not allow for exploration of an evolving social structure, including its gendered dimension.

Yet, the macro policy issues facing applied macroeconomists and governments in many cases have a clear gender dimension, particularly when we consider the labour market. Employment levels reflect a changing composition, with part-time female employment increasing relative to male full-time employment, for example. Vertical income distribution issues take on a gender dimension when associated with (predominantly female) one-parent families and child poverty. Horizontal income distribution issues take on a gender dimension when pay for female workers is lower than for male workers in the same occupations, and when girls are discouraged from acquiring skills in male-dominated occupations.

The feminist literature emphasises, even more than paid labour, the unpaid labour involved in care, predominantly provided by women (Himmelweit 2007). Paid care is normally also provided by women, and there are important interactions between the two modes of provision. These interactions evolve as societal norms evolve. The

\footnotetext{
${ }^{1}$ However, from a mainstream perspective, questions of social justice reflect moral judgement which are independent of theory.

${ }^{2}$ See further https://www.rebuildingmacroeconomics.ac.uk/projects/the-effects-of-income-gender-and-wealthinequality-and-economic-policies-on-macroeconomic-performance/
} 
reproduction of the labour force requires not only the biological input from parents but also nurturing and a whole range of household tasks. Rather than a cost to society, this is a contribution to society, without which, the economy could not function and reproduce itself. To consider care is to raise complex issues of quality of care, human motivation, and above all, social convention and power relations.

These considerations feed directly into the concerns of evolutionary economics with innovation, productivity and growth, all active areas for research supported by the availability of gender-specific data series. While evolutionary economics focuses on production within the firm, gendered macroeconomics emphasises production, within the household, of the means of production, notably of labour. The supply of skilled, healthy, well-adjusted labour depends on (predominantly unpaid) care. Macro outcomes thus depend on the social structures which support (or not) care.

In mainstream economics, the theoretical approach to gendered economic problems is instead to analyse gender differences in the same way as other apparently suboptimal outcomes, i.e. to identify factors which have impeded the full operation of market forces and thus impeded maximum efficiency. As far as non-market behaviour is concerned, the mainstream theory of family formation spearheaded by Becker (1981) treats it as an exemplar of rational choice, with intra-household bargaining leading to a stable Nash equilibrium which ensures an optimal outcome (subsumed in macroeconomic measures). ${ }^{3}$ On the other hand, some market outcomes are seen as suboptimal, such as unequal pay for equal work or unequal access to credit. But these are seen as market imperfections resulting from constraints such as (irrational) gender bias or information asymmetry. By implication, successfully eliminating these imperfections would remove the importance of gender as a subcategory of the population.

But here, we aim to take a broader view, both of macroeconomics and of gender. First we consider the nature of macroeconomics from a gender perspective. This will involve considering what is regarded as the proper subject matter of macroeconomics. We also consider the methodological approach to mainstream macroeconomics, including its inherent dualism and the privileging of the formal deductivist method, from a gender perspective. While mainstream economics applies a supposedly gender-neutral logical positivist approach to building knowledge, a feminist approach applies a different set of cognitive principles which have general application beyond gender. This discussion makes it apparent that the shortcomings of mainstream macroeconomics from a gender perspective, and the alternatives proposed in the feminist literature, provide a valuable focus for the wider non-mainstream critique of mainstream economics and efforts to pursue alternative approaches, as in evolutionary economics.

\section{The nature of macroeconomics: aggregation and the choice of variables}

The nature of modern macroeconomics is evident from its choice of variables among those which have monetary measures. The primary goal of macroeconomics is usually

\footnotetext{
${ }^{3}$ Feminist economists such as Folbre (1994, pp. 66-70) have used game theory to make particular arguments, but, unlike the Becker approach, do so as part of a pluralist methodology employing a range of types of argument.
} 
specified in terms of GDP growth, with a low rate of inflation and a low rate of unemployment as subsidiary goals (serving, and/or indicative of, economic growth respectively). Not only does this goal rely heavily on how exactly the domestic product is measured but it also presumes that this measure is a reasonable proxy for social welfare. It is a substantive question how far aggregate GDP growth meets the goals of different groups within society, including different genders.

It is usual for an introductory course to note the problems with GDP as a measure of societal welfare. It deflects attention from distributional concerns (gendered and otherwise). Further limiting attention to what has monetary value produces the odd implications that production of crime-fighting equipment adds to welfare as much as production of consumer goods, while some important welfare-enhancing activities, notably private care, are excluded. (GDP falls if a person marries their housekeeper.) Since women rather than men tend to be the main providers of care, this lack has considerable significance in terms of gender (see further Himmelweit 2013). Indeed, Robbins's (1932) definition of economics in terms of scarcity (rather than capacity for monetary measurement) implies that unpaid activity which employs scarce resources is in fact economic. But because of the absence of monetary measures in mainstream sources, unpaid private work continues to be absent from macroeconomic analysis.

The issue is not that gendered economics belongs in microeconomics rather than macroeconomics. Mainstream macro has been driven since the 1970s by the microfoundations' agenda, which requires all macroeconomic models to build on microfoundations (based on the rationality axioms applied to a representative agent). The outcome has been the dominance of macro by DSGE models which have been subjected to widespread critique for the limitations imposed by the representative agent (see e.g. Hendry and Meullbauer 2017; Stiglitz 2017). By subsuming gender, this framework inevitably is problematic for a gendered macroeconomics. In principle, some gender differences could be introduced into the standard framework, but they would require specification in terms of behavioural differences, or different endowments and/or constraints. The minefield that meeting such a requirement would represent reflects the analytical constraints imposed by the mainstream framework itself.

A primary characteristic of mainstream analysis is dualism, i.e. the practice of thinking in terms of mutually exclusive, all-encompassing pairs with fixed meaning and application, or duals - such as male/female. But increasingly attention among feminists is being paid to the intersectionality between gender and other characteristics, such as race, wealth, and geographical location. (Folbre 1994); each operates in terms of societal norms at the meso level. Dualism poses problems even for the gender classification itself, since gender is not in practice a dual-it can take multiple forms and indeed may be fluid. Yet, society has promoted a set of attitudes and has constructed institutional arrangements, which tend to force individuals into one of only two categories. Further, gender is arguably an emergent property: 'One is not born, but rather becomes, a woman', as de Beauvoir (1949, p. 1) famously pointed out (see also Butler 1990 on the social construction of gender). But where knowledge itself is socially constructed, 'gender serves as a cognitive organizer, based on the idea of metaphor as a basic building block of understanding' Nelson (1996: 3).

Further, identity issues apply to the distinction between the individual as separate from society (i.e. atomistic) and the individual as social. Even when mainstream theory 
incorporates the social dimension (e.g. in game theory), the ultimate motivation for social interaction is still self-interest (see e.g. Ashraf et al. 2005). Nevertheless, the distinction between selfish and other-directed behaviour has been used by feminist economists to tease out the implications of care being provided within and outside markets respectively. Braunstein et al. (2011) use this device in a modelling framework to analyse the macroeconomic endogeneity of paid and unpaid labour. It is important to note that drawing distinctions is not usually to be dualistic according to the definition set out above. Rather, they are a useful way of focusing on particular aspects of an issue within a broader analysis based on a nuanced understanding of a complex and evolving subject matter and where formal models constitute only part of the analysis.

Analysing care is a case in point. It is hard to analyse it in terms of constrained optimisation, since such an approach does not allow for such interdependent factors as affection, sympathy and a sense of moral obligation, all within a (meso) structure of societal norms. Social provisioning is a social process which is learnt and evolves (McMaster 2018). That it is usually women who are the carers might be put down to women having particular characteristics, e.g. being more emotional than men, an argument which seems to fly in the face of the 'universal' rational economic man model of human behaviour. But it also raises questions about the depiction of work as only causing disutility; if unpaid care is work, is it necessarily exploitative? Yet work can be fulfilling, and this applies particularly to care of family members. Schumacher (1974: ch. 4) showed how just reversing the normal mainstream classifications of work and consumption as causing disutility and utility, respectively, completely turns mainstream results on their head. ${ }^{4}$ The implication is that the mainstream framework, including the characterisation of work in general, needs a complete overhaul.

The mainstream model is part of a whole epistemological approach which is built on duals of which the male-female dual is only one (McCloskey 1983; Nelson 1996). The public/private dual, for example, leads to the household being 'exclusively regarded as the place of consumer spending and saving, but not as the location where the labour force is reproduced and where gender norms are reinforced and reproduced' (van Staveren 2017: 277). Dualism extends to scientific practice itself, with the rigour of the mainstream scientific method presented as the dual of intuition, precision the dual of vagueness, objectivity the dual of subjectivity, and so on. The former are all traditionally thought of as 'male' characteristics, while the latter are all traditionally thought of as 'female' characteristics.

The dualistic characterisation of gender feeds into a social/institutional process by which power is maldistributed, including cognitive power. The gender classification of characteristics is socially generated to a considerable extent. Indeed, if gendered nature is not in fact dualistic, then the 'male' characteristics do not apply universally to men, any more than the 'female' characteristics apply to all women. The implication of what has been discussed so far is that a feminist epistemology differs from the epistemology underlying male-dominated mainstream economics. But, as Richards (1980) argues, if epistemology were to be represented as a normal distribution, male and female epistemologies would be overlapping distributions. Nevertheless the distributional means are sufficiently distinct to allow us to think in terms of each having a characteristic epistemology (on average). Indeed, there are many leading non-mainstream male economists

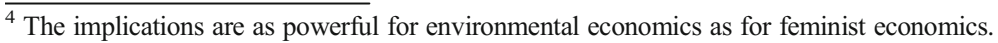


who adopt a different epistemological stance from the conventional approach, associating themselves with an epistemology normally characterised as female (on Keynes, see Forster-Broten 2017, and on Boulding, see McMaster 2018). Their epistemology followed from the prevalence of uncertainty in an open system (of knowledge and of society). Foster $(2011,2017)$ similarly explores the epistemology of evolutionary economics in relation to the uncertainty associated with an open, evolutionary social structure.

Perhaps the key concept here is 'otherness' (Kaul 2008). In a dualistic framework employing a 'masculine' epistemology, women are 'the other'; feminine characteristics are to be avoided, so that science can produce demonstrable truths to be held with certainty. But in a 'feminine' epistemology, to recognise otherness is not to reject 'science' but to recognise the situated nature of knowledge as a general phenomenon, i.e. an epistemology not peculiar to women. This naturally leads to thinking of knowledge as arising from human logic rather than deductivist classical logic, being provisional and subject to uncertainty, and something which requires persuasion, demonstration being impossible. This is the epistemology of the Scottish Enlightenment, which arose in the context of a country which had recently formed a union with a dominant neighbour - it was hard not to recognise otherness in such a situation.

The significance of this 'feminine' epistemology extends from philosophy to practice:

Feminist epistemology and philosophy of science ... identif[y] ways in which dominant conceptions and practices of knowledge attribution, acquisition, and justification systematically disadvantage women and other subordinated groups, and strives to reform these conceptions and practices so that they serve the interests of these groups (Anderson 2015).

The feminist cognitive approach governs the approach to building (provisional, uncertain) knowledge in macroeconomics. But it also governs behaviour with respect to knowledge in everyday practice, and particularly with respect to risk and uncertainty. Thus, for example, behavioural differences between genders have been found within the financial sector, leading to the Lehman Sisters Hypothesis that the collapse would not have happened if women had been in charge (see van Staveren 2014, but see Nelson 2016 for a different view). ${ }^{5}$ Such studies must of course take account of the fact that the women being studied already operate within a system of power relations, in employment, in society and in the household. But, that gendered epistemic differences have been seen by some to persist is significant, given the scope a hierarchical society provides for epistemic injustice (Anderson 2015).

\section{Gender as a focus for alternative approaches to macroeconomics}

There have been developments outside mainstream economics which are specifically addressed to gender issues, for example, the international movement to promote Gender Budgeting, to scrutinise government policy from a women's perspective. ${ }^{6}$ Since

\footnotetext{
${ }^{5}$ While uncertainty in financial markets encourages recourse to liquidity, van Staveren (2010: 1135) points to the role of care in relation to uncertainty.

${ }^{6}$ See https://wbg.org.uk/resources/what-is-gender-budgeting/
} 
women account for roughly half of the population, focusing on the rights of women is not exactly a minority interest. But the feminist literature demonstrates the wider macroeconomic implications of taking gender seriously than simple sectional interest. On one hand, focusing on gender sheds new light on consumption, saving and investment behaviour, as well as the more traditional feminist concerns with the labour market. On the other hand, the issues thrown up by considering economics from a feminist perspective resonate more widely within non-mainstream economics. It has been argued above that feminist epistemology potentially has much wider application. Indeed, the gender perspective provides a good context in which to consider how differently economics might be done.

One set of issues is raised by considering the nature of the individual, individual identity and the individual in society: "[f]eminist theory questions objectivity in knowledge production, argues for the importance of lived experience, and requires us to grapple with interconnected identities' (Forster-Broten 2017: Abstract). As Davis (2003) argues, identity is inherently social, undermining a dualistic categorisation of the individual and the social. Thus, gender identity is profoundly influenced by social norms. Further, interpersonal relationships, in the economy, in wider society and in the household, are conditioned by the social nature of identity. This perspective was addressed in Smith's ([1759] 1976) Theory of Moral Sentiments, where he further developed Hume's concept of sympathy. This human faculty employed the imagination, not only to understand experience from another's perspective but also to arrive at moral judgement. The moral motivation for particular behaviours (such as caring for others) arises both from a sense of fellow feeling with the caree and also from a sense of social obligation within a particular social structure.

It is the influence of the social, and the scope for broad generalisations (e.g. about the behaviour of women), which makes these characterisations of individual behaviour relevant to macroeconomics. That gendered analysis does not lend itself easily to deductivist mathematical formalism is not in itself a problem for an alternative epistemology. There may well be scope for mathematical formulations of particular arguments, to be put together with arguments arising from other methods. The key difference from a mainstream methodology is that in a Keynesian/feminist epistemology, a formal mathematical model cannot constitute a full argument with respect to a complex, open social system. The system is open not least because of the emergent nature of such key elements as gender, gendered behaviour and social norms.

Both Smith and Hume built all their philosophy (and economics as applied philosophy) on a theory of human nature. Drawing on detailed study of a wide range of cultures through history, they identified a commonality in human nature (among other things, this provided the foundation for their considerations of social justice). But they explained how human nature took on different forms in different contexts; by implication, gendered differences in behaviour are to a large extent the outcome of a particular socio-economic history. ${ }^{7}$

For example, a contributing factor in the emergent nature of gender identity was education, addressed not only to acquiring skills but also to personal transformation. Thus Smith ([1776] 1976: Vi.f.61) advocated education on the basis of its social, as much as personal, benefits. But education played an even more transformative role in

\footnotetext{
${ }^{7}$ See Foster (2017) on the importance of history for evolutionary economics.
} 
the nineteenth century for communitarians (such as Thomas Chalmers; see Dow et al. 2003). For them, moral education and community involvement in welfare assistance was the preferable means to reducing poverty compared with the anonymous and meagre welfare payments of the Poor Law. The communitarian system was paternalistic. Nevertheless, the model is one of transformative education and active community involvement in income redistribution and other forms of assistance, something which resonates with modern discussions about the most effective methods for international development assistance, particularly with respect to women and girls. The contrast between communitarianism and the Poor Law illustrates well the difference between an evolutionary focus on norms, ethics and processes at the meso level on the one hand, and optimising by atomistic agents on the other.

The rationale for assistance in the form of anonymous transfer payments presumes a given level of rationality. One of the duals employed in mainstream economics is that of rationality vis-à-vis emotion. This dual has entered significantly into macroeconomics amid attempts to theorise about crises. Emotion as the dual of rationality, e.g. a marked increase in uncertainty, is depicted as a shock capable of driving the economic system away from equilibrium. The policy motivation then is to 'nudge' behaviour into being more rational (Thaler and Sunstein 2008). But a non-dualistic treatment of emotion sees it not only as mediating observation of 'facts' but also as an integral element of behaviour (Dow 2011). Indeed, for Smith and Hume, emotion (the 'passions') was the foundation of all knowledge, providing the motivation to build it. For them, the complexity of social systems (as well as physical systems) was such that any knowledge was provisional, subject to uncertainty. The key to having a theory accepted was successful persuasion that it explained novel phenomena which, until satisfactorily explained, had caused emotional distress. Similarly, for Keynes (1936: chs 11 and 12), emotion was the driver of action in the form of firms undertaking real investment. Under uncertainty, reason alone could never justify such an action. Rather than being a dual, reason and emotion are complements. Since women are traditionally associated with the emotion side of the rational/emotional dual, this epistemology has particular resonance for gender studies and can draw profitably on feminist epistemology.

A further element common to the epistemology of Hume, Smith and Keynes was the role of social convention (habit and custom) as a basis for belief and action in the absence of sufficient contrary evidence to which reason might be applied. While social convention was the basis for much behaviour, it was the role of the philosopher (the expert) to challenge conventional belief in light of reason and evidence. It is clear that convention has played a key role in the experience of the different genders, while convention has periodically been subject to challenge and has evolved. An important example is the setting of wages. According to mainstream economics, wages are determined in the labour market as the value of marginal product, reflecting separable economic conditions rather than convention. In principle, then the market ensures a social optimum in the sense of efficiency-the mainstream approach being not to admit to any ingrained value judgements. Yet, while supply and demand play a part, it is evident that pay at all levels, and particularly relative pay for men and women, is substantially determined by conventional judgement that men should be paid more than women. This applies to CEOs whose pay is decided by peers on remuneration boards, to sports stars and to TV personalities as much as to part-time low-skilled workers. 
Mainstream macroeconomics requires theory to be formalised within equilibrium models built up on an axiomatic foundation referring to rational individual behaviour. A different approach, as outlined above, requires a different methodology, one more suited to analysing open, evolving systems. An open-system methodology involves drawing on a range of different types of argument in order to build up a picture which illuminates our understanding of reality. Since different schools of thought in economics understand that reality differently, each will identify a particular range of methods best suited to that understanding (see e.g. Dow 2013).

Feminist macroeconomics builds on feminist analyses at the meso level, i.e. analyses of conventions within the family, within the workplace and within relations with financial institutions. This is illustrated by the specification of formal feminist macroeconomic models, where such factors as gendered job segregation and the allocation of care labour by gender are incorporated in addition to the other economic and institutional characteristics of the economy under study (see e.g. Onaran 2015). This allows structured hypotheses in terms of broad characterisations of gendered behaviour whose macroeconomic implications can then be studied. Assessing such hypotheses empirically of course depends on data availability. There is much that can be achieved along these lines, effectively challenging conventional macroeconomic analyses which ignore gender distinctions.

Taking further the departures from mainstream thinking touched on above, however, poses new challenges and opportunities. For example, the use of GDP as a proxy for social welfare has been challenged, prompting some governments ${ }^{8}$ to set alternative goals in terms of a wider understanding of well-being - with their own data requirements. Further, we have emphasised here the evolutionary nature of the norms around gender. These tend to change slowly, such that gendered characteristics can be taken as (provisionally) given (not fixed) over time. But the analyst always needs to be alert to change over time. Further, these norms differ not only internationally but also within national societies, requiring consideration of more disaggregated approaches.

While many of the concerns with the mainstream approach refer to the poverty of its microfoundations, non-mainstream macroeconomics does not need to fit into a general, axiomatic structure (King 2012). Macroeconomics requires analysis in terms of aggregates, so generalisations are required as the basis for (provisional, context-specific) characterisations at the aggregate level. But, in line with our discussion of gender distinctions in terms of evolving social norms, the most appropriate grounding for enquiry as to the make-up of these aggregates is the meso level. As Foster (2011) argues with respect to evolutionary macroeconomics, what is required, rather than microfoundations for macroeconomics, is meso-foundations.

The challenge for feminist macroeconomics, as for all of non-mainstream economics, is to operationalise effectively the theoretical and empirical connections between the meso level and the macro level. Which generalisations and which subclassifications are reasonable for addressing particular policy questions about a particular context? The feminist macro literature demonstrates the fruitfulness of subclassifying conventional macro categories like consumption and investment by gender and explaining gender differences in terms of social norms. Other non-mainstream approaches can similarly break down conventional aggregates according to their particular focus. For evolutionary




macroeconomics as discussed here, the focus would be on context-specific, norm-bound, but evolving, complex systems, defined by their connection and lack of connection.

\section{Conclusion}

Gender is becoming a topic of interest to macroeconomists, not least because of the need for policy to address gender differences in such areas as income distribution and labour market behaviour. Disaggregation by gender has also been shown to challenge the results of mainstream analysis. But taking gender seriously exposes the limitations of the mainstream approach more broadly. According to this approach, beyond differences in endowments and preferences, any social justice issues arising from gender differences can only be treated as market imperfections which can, in principle, be eliminated. The tenacity of this approach to macroeconomics has been reinforced by the cognitive power of an approach to science which exemplifies 'male' characteristics.

Feminist epistemology rather is designed to address the key aspects of gendered economics: the emergent and non-dualistic nature of identity, the integral role of values and emotion in economic activity, the importance of (evolving) social convention and the role of power other than market power. These are also key aspects of political economy more widely, addressed by non-mainstream epistemology (deriving from Smith and Keynes). But, gender puts these issues into sharp focus, and gender studies have developed them in such a way as to inform non-mainstream economics more generally, and evolutionary economics in particular.

Acknowledgements This paper draws on a presentation at the Annual INET Conference, Edinburgh, October 2017. Comments from John Foster and Özlem Onaran are gratefully acknowledged.

\section{Compliance with ethical standards}

Conflict of interest The author declares that she has no conflict of interest.

Open Access This article is licensed under a Creative Commons Attribution 4.0 International License, which permits use, sharing, adaptation, distribution and reproduction in any medium or format, as long as you give appropriate credit to the original author(s) and the source, provide a link to the Creative Commons licence, and indicate if changes were made. The images or other third party material in this article are included in the article's Creative Commons licence, unless indicated otherwise in a credit line to the material. If material is not included in the article's Creative Commons licence and your intended use is not permitted by statutory regulation or exceeds the permitted use, you will need to obtain permission directly from the copyright holder. To view a copy of this licence, visit http://creativecommons.org/licenses/by/4.0/.

\section{References}

Anderson E (2015) Feminist Epistemology and Philosophy of Science. Stanford Encyclopedia of Philosophy. Available at https://plato.stanford.edu/entries/feminism-epistemology/. Accessed 9 October 2017

Ashraf N, Camerer CF, Loewenstein G (2005) Adam Smith, behavioral economist. J Econ Perspect 19(3): $131-145$

Becker GS (1981) A treatise on the family. Harvard University Press, Cambridge 
Braunstein E, van Staveren I, Tavani D (2011) Embedding care and unpaid work in macroeconomic modelling: a structuralist approach'. Fem Econ 17(4):5-31

Butler J (1990) Gender trouble: feminism and the subversion of identity. Routledge, London

Davis JB (2003) The theory of the individual in economics: identity and value. Routledge, London

de Beauvoir S (1949) La Deuxième Sexe, vol 2. Galliard, Paris

Dopfer K, Potts J (2008) The general theory of economic evolution. Routledge, London

Dopfer K, Foster J, Potts J (2004) Micro-meso-macro. J Evol Econ 14:263-279

Dow SC (2011) Cognition, sentiment and financial instability: psychology in a Minsky framework. Camb J Econ 35(2):233-250

Dow SC (2013) Methodology and post-Keynesian economics. In: Harcourt GC, Kriesler P (eds) Handbook of Post-Keynesian Economics. Oxford University Press, Oxford

Dow AC, Dow SC, Hutton A (2003) Thomas Chalmers and the economics and religion debate. In: Hum D (ed) Faith, reason and economics. St John's College Press, Winnipeg, pp 47-58

Folbre N (1994) Who pays for the kids? Gender and the structures of constraint. Routledge, London

Forster-Broten C (2017) Imaginative methods: a feminist rereading of John Maynard Keynes. College of Liberal Arts \& Social Sciences Theses and Dissertations, 232

Foster J (1987) Evolutionary macroeconomics. Allen and Unwin, London

Foster J (2011) Evolutionary macroeconomics: a research agenda. J Evol Econ 21(1):5-28

Foster J (2017) Prior commitment and uncertainty in complex economic systems: reinstating history in the core of economic analysis. Scot J Polit Econ 64(4):392-418

Foster J (2018) The consumption function: a new perspective. MPRA Paper No. 84383

Galbraith JK (2019) A global macroeconomics-yes, macroeconomics, dammit-of inequality and income distribution. Rev Keynes Econ 7(1):1-5

Hendry DF, Meullbauer JNJ (2017) The future of macroeconomics: macro theory and models at the Bank of England. University of Oxford Department of Economics, Discussion Paper no. 832

Himmelweit SF (2007) The prospects for caring: economic theory and policy analysis. Camb J Econ 31(4): 581-599

Himmelweit SF (2013) Care: feminist economic theory and policy challenges. J Gend Stud Ochanomizu Univ 16:1-18

Kaul N (2008) Imagining economics otherwise: encounters with identity/difference. Routledge, London

Keynes JM (1936) The general theory of employment, interest and money. Macmillan, London

King J (2012) The microfoundations delusion: metaphor and dogma in the history of macroeconomics. Edward Elgar, Cheltenham

McCloskey DN (1983) The rhetoric of economics. J Econ Lit 21:434-461

McMaster R (2018) Does post Keynesianism need a theory of care? In: Dow SC, Jespersen J, Tily G (eds) Money, Method and Contemporary Post-Keynesian Economics. Edward Elgar, Cheltenham

Nelson JA (1996) Feminism, objectivity and economics. Routledge, London

Nelson JA (2016) Not-so-strong evidence for gender differences in risk taking. Fem Econ 22(2):114-142

Onaran Ö (2015) The role of gender equality in an equality-led sustainable development strategy. Greenwich Papers in Political Economy, no. GPERC26

Onaran Ö, Oyvat C, Fotopoulou E (2018) Gendering macroeconomic analysis and development policy: a theoretical model for gender equitable development. Paper presented at the Care, Work and the Economy Workshop, 21 October, Berlin

Richards J (1980) The sceptical feminist: a philosophical enquiry. Routledge, London

Robbins L (1932) An essay on the nature and significance of economic science. Macmillan, London

Schumacher EF (1974) Small is beautiful: economics as if people mattered. Sphere Books, London

Seguino S (2010) Gender, distribution, and balance of payments constrained growth in developing countries. Rev Polit Econ 22(3):373-404

Smith A ([1759] 1976) The theory of moral sentiments, Glasgow edition, edited by Raphael DD, Macfie A, Oxford University Press, Oxford

Smith, A ([1776] 1976) An inquiry into the nature and causes of the wealth of nations, edited by Campbell RH, Skinner AS, textual editor Todd WB. Oxford University Press, Oxford

Stiglitz JE (2017) Where modern macroeconomics went wrong. NBER Working Paper No. 23795

Thaler R, Sunstein C (2008) Nudge. Penguin Books, Harmondsworth

van Staveren I (2010) Post-Keynesianism meets feminist economics. Camb J Econ 34:1123-1144

van Staveren I (2014) The Lehman sisters hypothesis. Camb J Econ 38(5):995-1014

van Staveren I (2017) Beyond stimulus versus austerity: pluralist capacity building in macroeconomics. Eur J Econ Econ Policies Interv 4(2):267-281 